\title{
ENERGY EFFICIENT DESIGN OF AUTONOMOUS VEHICLE BASED STORAGE AND RETRIEVAL SYSTEM
}

\author{
Anil Akpunar* \\ Yasar University, Department of Industrial Engineering, Turkey \\ Banu Yetkin Ekren \\ Yasar University, Department of Industrial Engineering, Turkey \\ Tone Lerher \\ University of Maribor, Faculty of Mechanical Engineering, Slovenia
}

Autonomous warehousing is moving beyond traditional crane-based AS/RS technologies on the way to autonomous vehicle (AV) based AS/RS (AVS/RS) technologies. AVS/RS proposes substantial flexibility with respect to throughput capacity in the transfer of unit loads in high density storage areas due to having opportunity in changing the number of AVs in the system. Because of recent trend in ecological concern, an efficient AVS/RS warehouse design should not only consider minimization of cycle time of a transaction to process but also consider the minimization of energy consumption in the system. In this study, we explore energy minimum AVS/RS warehouse design providing maximum utilization of resources in the system. We consider, rack design in terms of number of aisles, tiers and bays as well as number of AVs as decision variables in the design and, energy minimization as objective function. We completed 81 simulation experiments for different levels of those decision variables and provide the results via a histogram graph.

Key words: Automated warehouse, AVS/RS, Simulation, Warehousing

\section{INTRODUCTION}

Warehouses are critical for supply chain. Although companies would like to follow "make to order" production policy, warehouses exist to consolidate demands, to reduce transportation cost and response time, to achieve economies of scale. There are typically two types of warehouses: production warehouses and distribution centres (DCs). DCs are key components in sup- ply chain because of having vital role in obtaining materials from different suppliers, performing value-added activities, and assembling (or sorting) them to fulfil customer orders. While DCs deliver some level of service to manufacturers and customers by providing material handling and storage capabilities, this comes at a cost. Hence, an efficient design of DC is significant to provide a better flow of material and to reduce these facility logistics costs.

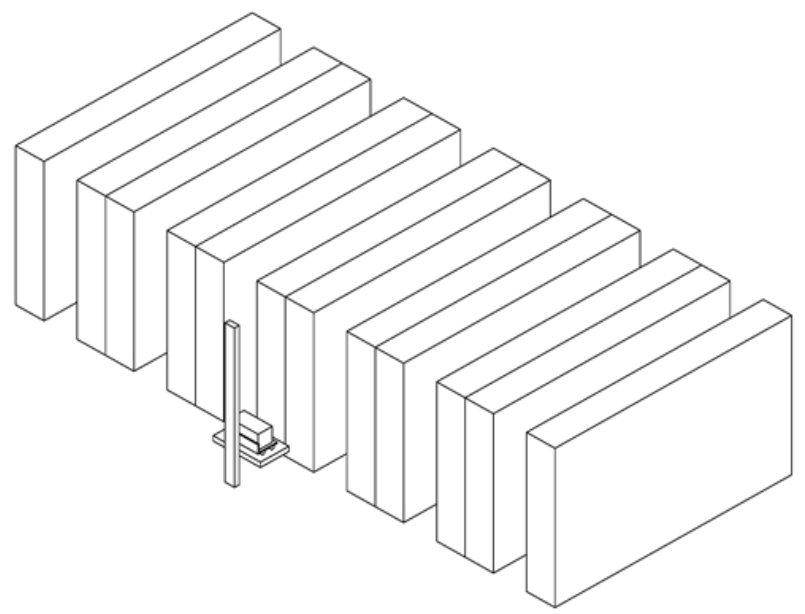

Figure 1: An AVS/RS warehouse

* Yasar University, No: 37-39, Bornova, Izmir, Turkey; 


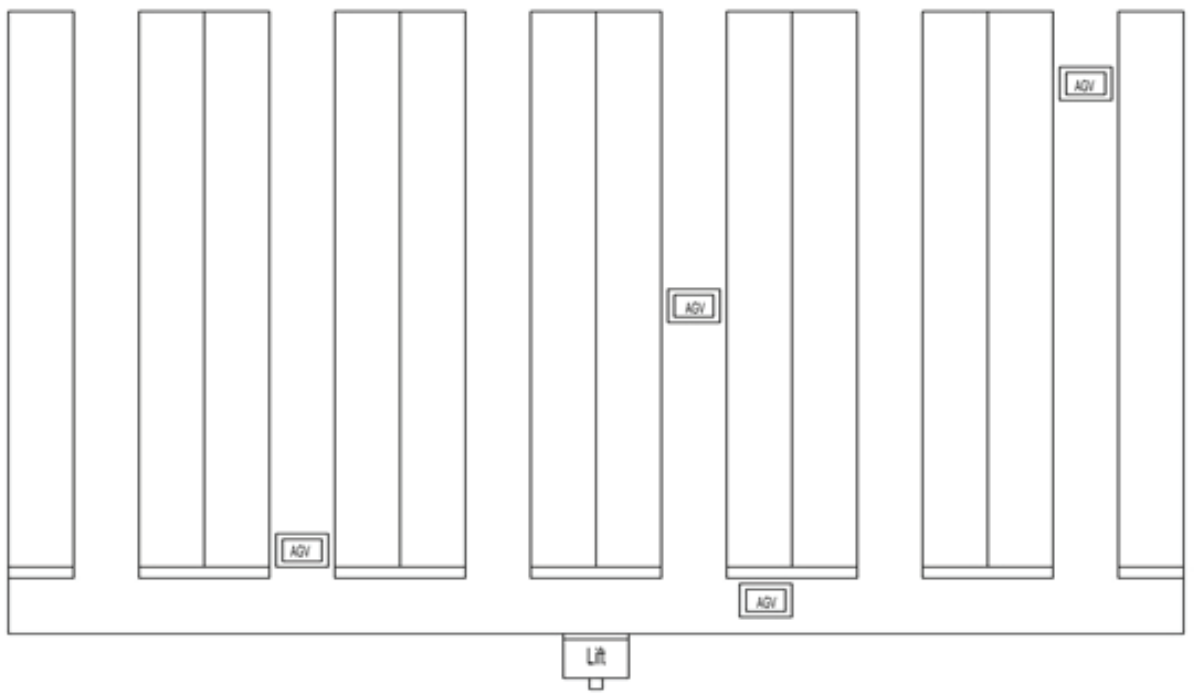

Figure 2: Top view of an AVS/RS

In this paper, we focus on a widely used automated storage and retrieval system by DCs: AVS/RS (Figures 1-2). An AVS/RS consists of AVs, lifts and storage racks. AVs function as storage and retrieval device and, follow a sequential travel pattern in the horizontal direction. Lifts are used by $A V s$ for vertical movement. An alternative system to AVS/RS is the traditional crane-based automated storage and retrieval system (CBAS/ $\mathrm{RS})$. AVS/RSs are more flexible in the adaptability of system throughput capacity to transactions demand by allowing the designer to change the number of vehicles operating in a fixed storage configuration as necessary. For example, increasing the number of vehicles decreases the transaction cycle times and utilization which are also key measures of system performance.

There are several factors that should be considered in the design concept of AVS/RS to meet the supply chain requirements. The existing studies in literature about AVS/RS, mostly focus on warehouse design minimizing performance values of average cycle time of transactions as well as queue lengths and utilization of lifts and AVs. However, due to recent trends on ecological concerns, an automated warehouse design should also consider minimization of energy (i.e., electricity) consumption and hence CO2 oscillation released to the atmosphere by these systems. By considering minimization of energy consumption, operational cost of these systems and more importantly, negative environmental effects of these systems will also be decreased. The novelty and contribution of this study can be summarized as in below:
- Different from the existing studies, we approach to an AVS/RS warehouse design problem from an energy efficiency view by minimizing the average electricity consumption per transaction in the system.

- Several design inputs (decision variables) such as rack design in terms of number of bays, aisles and tiers as well as number of AVs are considered as decision variables.

By minimizing the average energy consumption per transaction in the system, we aim to contribute to EU's future decreased $\mathrm{CO} 2$ emission target.

\section{LITERATURE REVIEW}

AnAVS/RS was first studied by Malmborg (2002). In this system, autonomous vehicles, typically used for heavy unit loads, have the capability to move between tiers and aisles. Later on, Malmborg (2003) proposed a state equation model for predicting the proportion of dual command (DC) cycles. The model that he proposed provides a useful tool for estimating DC cycles in AVS/RS.

Kuo, Krishnamurthy, and Malmborg (2007) developed a computationally efficient cycle time model for AVS/RS, estimating resource utilization. They solved different scenarios to show the performance of the model. Their model could provide estimates of vehicle utilization and system cost with a (high) degree of accuracy.

Kuo et al. (2008) studied a queuing network model to estimate some performance measures for AVS/RS where class-based storage policies may be used to mitigate the cycle-time inflation effects of storage. The model is capable of effi- 
ciently generating estimates of AVS/RS resource utilization based on alternative class-based storage schemes.

Fukunari and Malmborg (2008) developed an efficient cycle time model for AVS/RS, comparing its performance with CBAS/RS. The developed model is based on an iterative computational scheme based on random storage assumptions and queuing model approximations. The procedure is shown using realistically-sized problems.

Later, Fukunari and Malmborg (2009) proposed a queuing network approach for the prediction of resource utilizations in AVS/RSs. This technique provides reasonably accurate estimates of the resource utilization measures that are essential to the process of system conceptualization.

Zhang, Krishnamurthy, Malmborg, and Heragu (2009) studied variance-based approximation for waiting times in AVS/RS. They modeled the system using a series of queuing approximations, by dynamically selecting between three alternative queuing approximations based on the squared coefficient of variation (SCV) of transaction interarrival times. The results of the proposed model show greater accuracy in estimation of transaction waiting times, thereby enabling more effective design conceptualization. They also incorporated the proposed models into online tools to enable warehouse designers and analysts develop alternative AS/RS and AVS/RS warehouse configurations.

In recent work, Ekren, Heragu, Krishnamurthy, and Malmborg (2010), Ekren (2011), and Ekren and Heragu (2011) studied simulation-based performance evaluation of AVS/RS. In these works, two approaches were taken. The first was the use of regression based analysis to investigate near optimum configuration design under predesigned scenarios for number of vehicles and lifts in the system (Ekren and Heragu, 2010). The second was the implementation of experiments for an AVS/RS to identify factors affecting its performance (Ekren, Heragu, Krishnamurthy, and Malmborg (2010)).

Roy et al. (2012) proposed a semi-open queuing network (SOQN) model to evaluate design trade-offs in a single tier of an AVS/RS. Their model captures the effect of location of the vehicles within a tier using multiple vehicle classes and class switching probabilities. Because exact solutions to the semi-open queuing network are not available, they proposed a decomposition approach. Model results suggest benefits of having multiple zones due to reduction in travel time along the cross-aisle. Ekren, Heragu, Krishnamurthy, and Malmborg $(2013,2014)$ also employed queuing network to model an AVS/ RS showing that the system could efficiently be modelled using a semi-open queuing network. As mentioned previously, we approach to the AVS/RS design problem from an energy efficiency view by minimizing electricity consumption in the system. We also considered several design inputs (decision variables) such as rack design in terms of number of bays, aisles and tiers as well as number of $\mathrm{AVs}$ as decision variables.

\section{SIMULATION MODEL AND ENERGY CONSUMPTION CALCULATIONS}

The simulation model's flow chart is given in Figure 3. A specific number of vehicles is assigned to each zone. Therefore, a vehicle always uses the same lift for its vertical movement.

The assumptions that are used in the simulation model are:

- The warehouse in divided into homogenous zones in terms of number of bays, aisles, tiers and number of AVs.

- Each zone has one lift system.

- The dwell point of an AV is the place where the last storage or retrieval transaction is completed.

- The dwell point of the lift is where the last vertical movement is completed.

- The system uses pure random storage policy.

- The transactions are served by the vehicles on a dual command rule.

- The vehicles requiring lifts for vertical movement are served by FCFS order.

- The single-deep racks on either side of an aisle consist of bays, and each bay can hold three unit loads.

- Unit loads are transferred by the conveyors and arrive to the I/O locations.

- The simulation is run for one year with one month warm-up period and one replication.

- In the simulation model, the "common random variables" (CRN) variance reduction technique is used.

- The considered mass values for $\mathrm{AVs}(\mathrm{mV})$, lifts $(\mathrm{mL})$ and pallets $(\mathrm{mP})$ are $150 \mathrm{~kg} ., 350$ kg., and 1000 kg., respectively. 


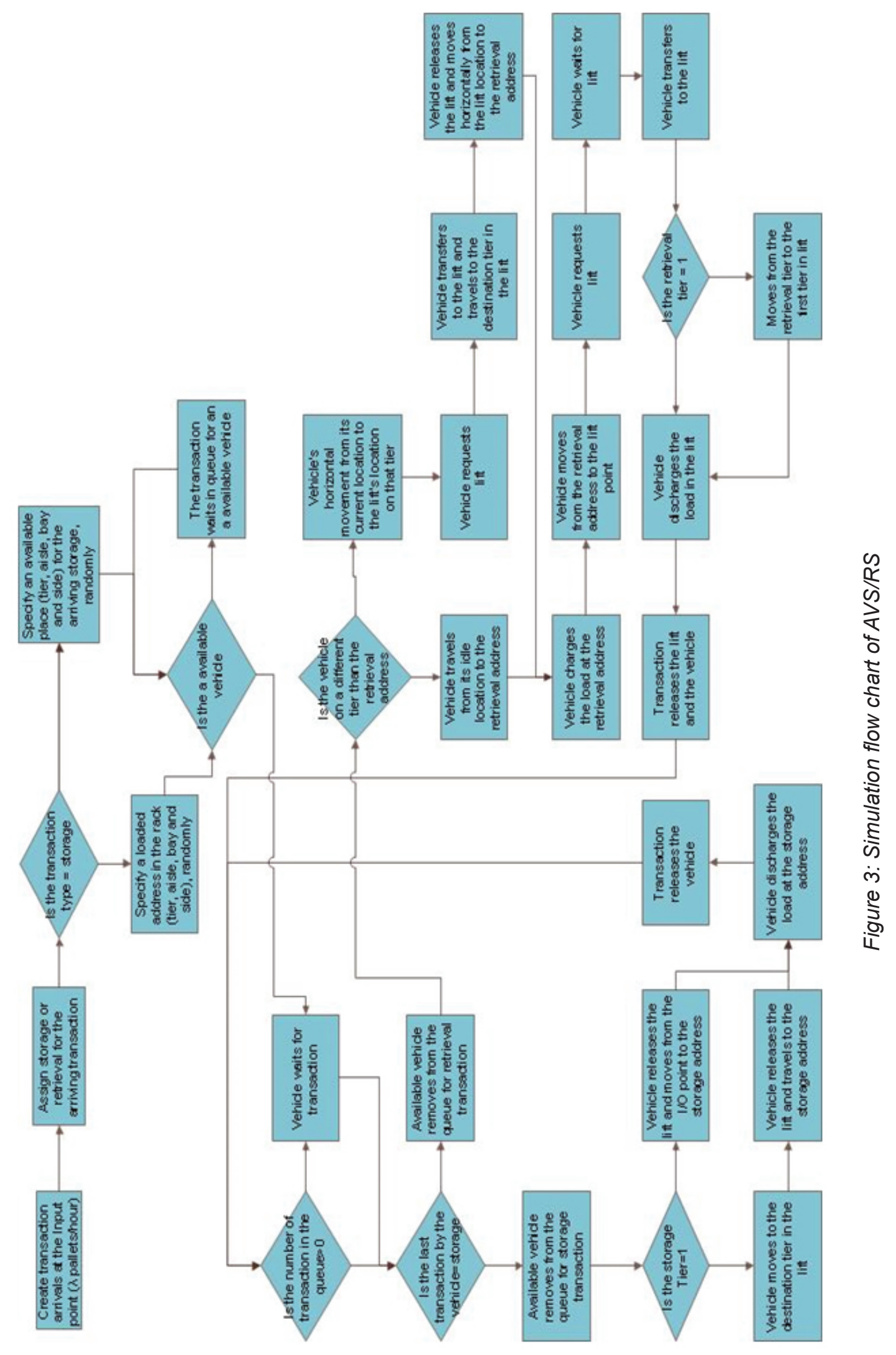


The validation of the simulation model is completed by the previous papers of Ekren B.Y. (Ekren B.Y., 2011; Ekren et al., 2010; Ekren and Heragu, 2011; Ekren and Heragu, 2010).

\section{A.Travel Time Calculations for AVs and Lifts}

In the simulation model, the energy (electricity) consumption calculations are completed for AVs and lifts, separately by considering the conditions that they are accelerating, decelerating or traveling at the maximum velocity.

Since the amount of electricity consumptions depend on the acceleration, deceleration and the steady state (at the maximum speed) traveling conditions of the AVs and lifts, we need to define velocity versus time relationship graphs. For that, we define two cases where $\mathrm{AV} /$ /ift reaches to its maximum speed (Case I) or not (Case II). Before presenting the details of the energy consumption calculations, we provide the notations that are used in this paper.

$A$ : number of tiers in an aisle

$B$ : number of bays in a tier of an aisle

$L$ : number of lifts in the warehouse

$N_{v}$ : number of vehicles assigned to each lift (zone)

$V_{\max }:$ the maximum velocity that an $A_{V}$ or a lift can reach $(\mathrm{m} / \mathrm{sec})$

$V_{\text {last }}$ : the last velocity that an AV or lift reaches (due to short distance $\left.V_{\text {last }}<V_{\text {max }}\right)(\mathrm{m} / \mathrm{sec})$

$a_{V}$ : acceleration value of AV $\left(\mathrm{m} / \mathrm{sec}^{2}\right)$

$d_{v}$ : deceleration value of AV $\left(\mathrm{m} / \mathrm{sec}^{2}\right)$

$a_{L}:$ acceleration value of lift $\left(\mathrm{m} / \mathrm{sec}^{2}\right)$

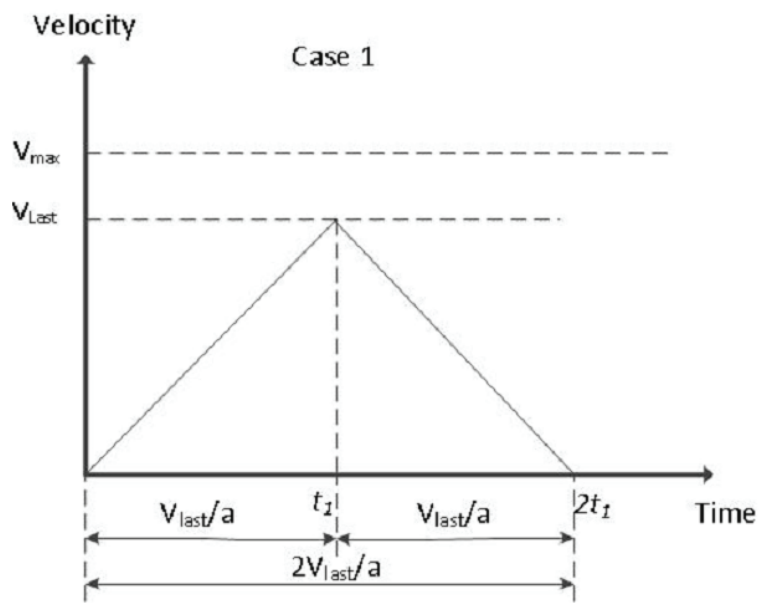

Figure 4: Case I
$d_{L}$ : deceleration value of lift $\left(\mathrm{m} / \mathrm{sec}^{2}\right)$

$G$ : force of gravity $\left(\mathrm{G}=\mathrm{mg}-\mathrm{kgm} / \mathrm{sec}^{2}-\mathrm{N}\right)$

$m_{V}$ : mass of AV $(150 \mathrm{~kg})$

$m_{L}$ : mass of lift $(350 \mathrm{~kg})$

$m_{p}$ : mass of pallet $(1000 \mathrm{~kg})$

$g$ : standard gravity $\left(10 \mathrm{~m} / \mathrm{sec}^{2}\right)$

$c_{r}$ : resistant coefficient $(=0.01)$

$f_{r}$ : factor for resistance of rotating masses with variable speed $(=1.15)$

$F_{T}$ : traction force in the acceleration (Newton)

$F_{B}$ : traction force in braking (Newton)

$F_{C}$ : traction force in travel with constant velocity (Newton)

$P_{T}$ : engine power to overcome $\mathrm{FT}(\mathrm{kW})$

$P_{B}$ : engine power to overcome FB $(\mathrm{kW})$

$P_{C}$ : engine power to overcome $\mathrm{FC}(\mathrm{kW})$

$F_{L}$ : lifting force (Newton)

$P_{L}$ : engine power to overcome $\mathrm{FL}(\mathrm{kW})$

$W_{A}$ : amount of energy (electricity) consumption in acceleration case $(\mathrm{kWh})$

$W_{D}$ : amount of energy (electricity) consumption in deceleration case $(\mathrm{kWh})$

$W_{c}$ : amount of energy (electricity) consumption in travel with constant velocity case (kWh)

Figure 4-5 show travel distance versus travel time graphs of lifts/AVs. By utilizing these graphs, how long an AV or lift accelerates/decelerates and travels with constant velocity can be calculated easily. In Figures 4-5, since it is assumed that acceleration value is equal to deceleration value, the time spent in acceleration and deceleration will be equal in two cases. It should be

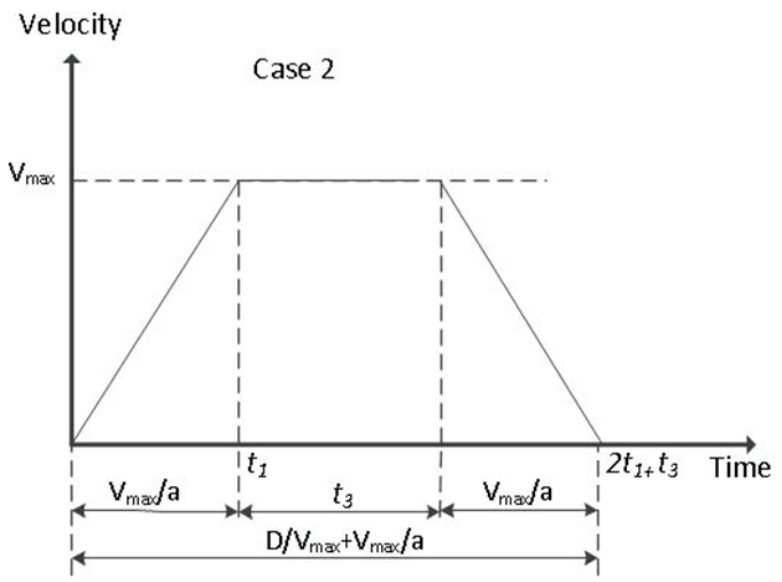

Figure 5: Case II 
noted that the area under these graphs will provide the distance travelled (D) by lifts/AVs.

For instance, in Figure 4, D is calculated by (1):

$V_{\text {last }}=a_{t 1}$

$t_{1}=\sqrt{D / a}$

$D=V_{\text {last }} t_{1}$

Where $V_{\text {last }}$ is calculated by (2) and $t_{1}$ is calculated by (3):

In Figure 5, lift/AV is able to reach to its maximum velocity due to the longer travel distance. It accelerates/decelerates $t_{1}(\mathrm{sec})$ amount of time and travels with constant velocity (i.e., with its maximum velocity) for $t_{3}(\mathrm{sec})$ amount of time. By assuming that acceleration and deceleration values are equal, Vmax is calculated by (4):

$V_{\max }=a t_{1}$

Hence, the total travel time in Case II be(50mes as in (5):

$2 \mathrm{t}_{1}+\mathrm{t}_{3}=\mathrm{D} / \mathrm{V}_{\text {max }}+\mathrm{V}_{\text {max }} / \mathrm{a}$

\section{B.Energy Consumption Calculations for AVs}

Based on Case I and II, an AV can realize two types of travels based on whether it reaches to its maximum velocity or not. Note that in Case $\mathrm{I}-\mathrm{II}$, it is assumed that vehicle accelerates/decel-

$F_{T}=G c_{r}+G / g a_{s} f_{r}\left(\right.$ Newton $\left.-\mathrm{kg} \mathrm{m} / \mathrm{sec}^{2}\right)$

erates $t_{1}$ amount of the time.

In the acceleration case, the traction force is cal-

$P_{T}=F_{T} V_{\text {Last }} / \eta$

culated by (6):

The required engine power to overcome $F_{T}$ as

$F_{B}=G / g d_{s} f_{r}-G c_{r}$

$\mathrm{kW}$ is calculated by (7):

In the deceleration case, the braking force is cal-

$P_{B}=\frac{F_{B} \cdot V_{\text {last }}}{1000 \cdot \eta}$

culated by (8):

The required engine power to overcome $F_{B}$ as

$F_{C}=G \cdot C_{r}\left(\right.$ Newton $\left.-\mathrm{kg} \mathrm{m} / \mathrm{sec}^{2}\right)$

$\mathrm{kW}$ is calculated by (9).

In the travel case with constant velocity, the trac-
$P_{C}=\frac{F_{C} \cdot V_{\max }}{1000 \cdot \eta}(\mathrm{kW})$

tion force is calculated by (10):

The required engine power, $\mathrm{PC}$, to overcome $\mathrm{FC}$ as $\mathrm{kW}$ is calculated by (11).

Hence, the energy (electricity) consumption in

$$
\begin{aligned}
& W_{A}=P_{T} \cdot t_{1}(\mathrm{kWh}) \\
& W_{D}=P_{B} \cdot t_{1}(\mathrm{kWh}) \\
& W_{C}=P_{C} \cdot t_{2}(\mathrm{kWh})
\end{aligned}
$$

acceleration deceleration and constant velocity travel case for vehicle can be calculated by (12)-(14) respectively:

\section{C.Energy Consumption Calculations for Lifts}

In the lift case, travel time calculations do not change however, because lifts overcome/utilize the gravity force in travelling upper/lower levels,

$F_{L}=G+\frac{G}{g} \cdot a_{L} \cdot f_{r}\left(\right.$ Newton $\left.-\mathrm{kg} \mathrm{m} / \mathrm{sec}^{2}\right)$

the energy consumption calculations change.

In the acceleration case, the lifting force is calcu-

$P_{L}=\frac{F_{L} \cdot V_{\text {last }}}{1000 \cdot \eta}$

lated by (15):

The required engine power to overcome $\mathrm{FL}$ as

$F_{B}=G+\frac{G}{g} \cdot d_{L} \cdot f_{r}\left(\right.$ Newton $\left.-\mathrm{kg} \mathrm{m} / \mathrm{sec}^{2}\right)$

$\mathrm{kW}$ is calculated by (16):

In the deceleration case, the braking force is cal-

$P_{L}=\frac{F_{L} \cdot V_{\text {last }}}{1000 \cdot \eta}$

culated by (17):

The required engine power to overcome FB as

$F_{C}=G\left(\right.$ Newton $\left.-\mathrm{kg} \mathrm{m} / \mathrm{sec}^{2}\right)$

$\mathrm{kW}$ is calculated by (18).

In the travel case with constant velocity, the trac-

$P_{C}=\frac{F_{C} \cdot V_{\max }}{1000 \cdot \eta}(\mathrm{kW})$

tion force is calculated by (19):

The required engine power, $\mathrm{PC}$, to overcome FC as $\mathrm{kW}$ is calculated by (20).

Hence, the energy (electricity) consumption in

$W_{A}=P_{L} \cdot t_{1}(\mathrm{kWh})$ 
$W_{D}=P_{B} \cdot t_{1}(\mathrm{kWh})$

$W_{C}=P_{C} \cdot t_{2}(\mathrm{kWh})$

acceleration deceleration and constant velocity travel case of lift can be calculated by (21)-(23) respectively.

\section{EXPERIMENTS CONDUCTED IN SIMULATION MODEL}

We conducted experiments based on different three input levels of number aisles - A -, number of bays - B -, number of tiers - T-, such that they provide the total number of storage capacity as 55,000 pallets $(A \times B \times T \times 2$ sides $\times 3$ pallets/bay). Each bay has 3 pallet areas. Table 1 summarizes the scenarios that are run in the simulation models.

Table 1: Conducted experiments in simulation

\begin{tabular}{|c|c|c|c|}
\hline $\boldsymbol{L}$ & $\boldsymbol{N V}$ & $\boldsymbol{T}$ & $\boldsymbol{A}$ \\
\hline 6 & 2 & 5 & Low $(40,4254)$ \\
\hline 7 & 3 & 7 & Medium $(48,56,60)$ \\
\hline 8 & 4 & 9 & $\operatorname{High}(64,63,66)$ \\
\hline
\end{tabular}

It should be noted that after running the Table 1 experiments, we obtained two performance measures from the system. These are: average energy consumption per transaction (EC) as kWh, average utilization of lifts (UL) and, average utilization of AVs (UV).

Note that in Table 1, there are $34=81$ possible combinations to experiment. Hence, we completed 81 experiments in simulation and observed their results. To be able to have 55,000 storage capacity, based on the chosen $A$ value, $B$ is calculated by $B=55,000 /(A \times T \times 2$ sides $\times$ 3 pallets/bay) and it is rounded up to the closest integer value. Hence, in the warehouse design concept, $\mathrm{B}$ can be seen as not a design parameter because $B$ depends on $A$. The value of $A$ is defined by considering a divisible and practical value based on the $L$ value (i.e., number of lifts $-L$ ). Note that NV indicates the number of vehicles assigned to each lifts.

Table 2 shows, the combinations and the results of 81 experiments sorted in the ascending order of values Ec. Since we consider practical performance values for average utilization values for lifts/vehicles (i.e., lower than 95\%), we filtered these 81 designs so that we they provide utilization values for lifts and $\mathrm{AVs}$, namely lower than $95 \%$. After filtering, the number of designs reduced to 56 . Figure 6 summarizes these 56 ex- periments via histograms. The $x$-axis shows the designs and the $y$-axis shows the Ec values. In Figure 6, the average utilization values of lifts and AVs are also shown. The practitioner may prefer the 2nd design to reduce its Ec. In this design $L=8, N v=16$ and $T=5$.

Some findings from Figure 6 are summarized below:

- When number of tiers increases, the energy consumption per transaction also increases probably due to large portion of the lift energy consumption.

- In the fixed number of tier designs having large number of bays causes increased energy consumption (deep storage aisles).

- When the warehouse has large footprint, (i.e., low $T$ and high A values) the energy consumption tends to decrease.

\section{CONCLUSION}

In this study, we analyzed energy consumption per transaction changes based on warehouse design of an autonomous vehicle based storage and retrieval system. 81 simulation experiments are completed based on different design inputs of number of tiers, lifts and aisles as well as autonomous vehicles in the system. We filtered the results by considering the designs whose utilization values of $A V s$ and lifts are lower than 95\%. The results are presented via a histogram graph in Figure 6. By this figure, the decision maker can define the warehouse design that fits to his/ her requirements.

\section{REFERENCES}

1) Ekren, B.Y. 2011. Performance evaluation AVS/RS under various design scenarios: a case study International Journal of Advanced Manufacturing Technology, 55 1253-1261.

2) Ekren, B.Y., S.S. Heragu, A. Krishnamurthy, C.J. Malmborg. 2010. Simulation based experimental design to identify factors affecting performance of AVS/RS. Computers \& Industrial Engineering 58 175-185.

3) Ekren, B.Y., S.S. Heragu, A. Krishnamurthy, C.J. Malmborg. 2013. An approximate solution for semi-open queuing network model of autonomous vehicle storage and retrieval system IEEE Transactions on Automation Science and Engineering, 10 205-215.

4) Ekren, B.Y., S.S. Heragu, A. Krishnamurthy, 
C.J. Malmborg. 2014. Matrix-geometric solution for semi-open queuing network model of autonomous vehicle storage and retrieval system Computers \& Industrial Engineering, 68 78-86.

5) Ekren, B.Y., S.S. Heragu. 2010. Simulation based regression analysis for the rack configuration of autonomous vehicle storage and retrieval system International Journal of Production Research, 48(21) 6257-6274.

6) Ekren, B.Y., S.S. Heragu. 2011. Simulation based performance analysis of an autonomous vehicle storage and retrieval system Simulation Modelling Practice and Theory, 19 1640-1650.

7) Fukunari, M., C.J. Malmborg. 2008. An efficient cycle time model for autonomous vehicle storage and retrieval systems. International Journal of Production Research 46(12) 3167-3184.

8) Fukunari, M., C.J. Malmborg. 2009. A network queuing approach for evaluation of performance measures in autonomous vehicle storage and retrieval systems. European Journal of Operational Research 193(1) 152-167.

9) Hibbeler, R.C. (2010) Engineering Mechanics - Dynamics, 12th edition, Pearson.

10) Kuo, P. H., A. Krishnamurthy, C.J. Malmborg. 2007. Design models for unit load storage and retrieval systems using autonomous vehicle technology and resource conserving storage and dwell point policies. Applied
Mathematical Modelling 31(10) 2332-2346.

11) Kuo, P.H., A. Krishnamurthy, C.J. Malmborg. 2008. Performance modelling of autonomous vehicle storage and retrieval systems using class-based storage policies. International Journal of Computer Applications in Technology 31(3-4) $238-248$.

12) Malmborg, C.J. 2002. Conceptualizing tools for autonomous vehicle storage and retrieval systems. International Journal of Production Research 40(8) 1807-1822.

13) Malmborg, C.J. 2003. Interleaving rule dynamics in autonomous vehicle storage and retrieval systems. International Journal of Production Research 41(5) 1057-1069.

14) Roy D., S.S. Heragu, A. Krishnamurthy, C.J. Malmborg. 2012. Performance analysis and design trade-offs in warehouses with autonomous vehicle technology. IIE Transactions 44(12) 1045-1060.

15) Zhang, L., A. Krishnamurthy, C.J. Malmborg, S.S. Heragu. 2009. Variance-based approximations of transaction waiting times in autonomous vehicle storage and retrieval systems. European Journal of Industrial Engineering 3(2) 146-168.

\section{ACKNOWLEDGEMENT}

Paper sent to revision: 12.01.2016.

Paper ready for publication: 24.02.2017. 


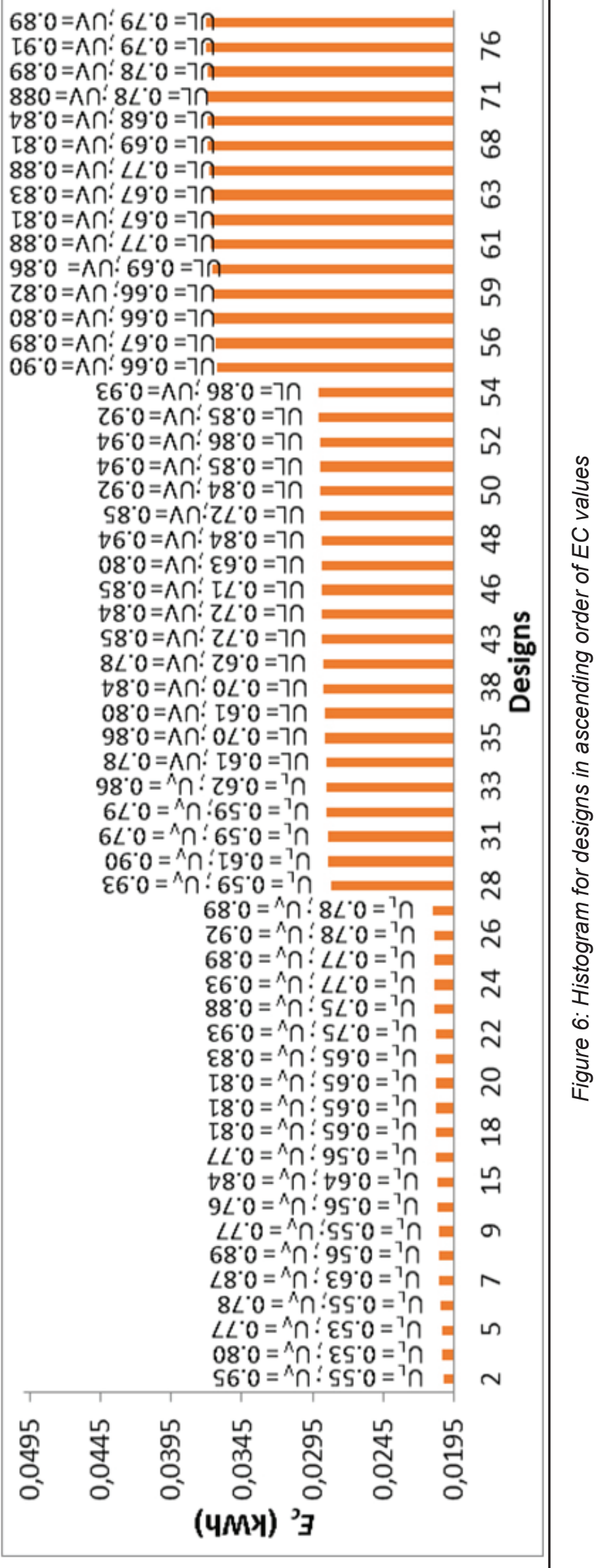


Table 2: Results of conducted experiments in simulation

\begin{tabular}{|c|c|c|c|c|c|c|c|c|c|c|c|c|c|}
\hline \multirow{2}{*}{ Sc. } & \multicolumn{3}{|c|}{ Rack Design } & \multicolumn{3}{|c|}{ Performance Measures } & \multirow{2}{*}{ Sc. } & \multicolumn{3}{|c|}{ Rack Design } & \multicolumn{3}{|c|}{ Performance Measures } \\
\hline & $\mathbf{L}$ & $\mathbf{N}_{\mathrm{v}}$ & $T$ & $\mathrm{E}_{\mathrm{c}}$ & $U_{L}$ & $\mathbf{u}_{\mathrm{v}}$ & & $\mathbf{L}$ & $\mathbf{N}_{\mathrm{v}}$ & $\mathbf{T}$ & $\mathrm{E}_{\mathrm{c}}$ & $U_{L}$ & $\mathbf{U}_{\mathrm{v}}$ \\
\hline 1 & 8 & 16 & 5 & 0.0200 & 0.53 & 1.00 & 42 & 6 & 12 & 7 & 0.0288 & 0.75 & 1.00 \\
\hline 2 & 8 & 16 & 5 & 0.0202 & 0.55 & 0.95 & 43 & 7 & 21 & 7 & 0.0288 & 0.72 & 0.85 \\
\hline 3 & 7 & 14 & 5 & 0.0203 & 0.63 & 1.00 & 44 & 6 & 12 & 7 & 0.0288 & 0.76 & 1.00 \\
\hline 4 & 8 & 24 & 5 & 0.0203 & 0.53 & 0.80 & 45 & 7 & 21 & 7 & 0.0289 & 0.72 & 0.84 \\
\hline 5 & 8 & 32 & 5 & 0.0203 & 0.53 & 0.77 & 46 & 7 & 28 & 7 & 0.0289 & 0.71 & 0.85 \\
\hline 6 & 8 & 24 & 5 & 0.0204 & 0.55 & 0.78 & 47 & 8 & 32 & 7 & 0.0289 & 0.63 & 0.80 \\
\hline 7 & 7 & 21 & 5 & 0.0205 & 0.63 & 0.87 & 48 & 6 & 18 & 7 & 0.0289 & 0.84 & 0.94 \\
\hline 8 & 8 & 16 & 5 & 0.0205 & 0.56 & 0.89 & 49 & 7 & 28 & 7 & 0.0289 & 0.72 & 0.85 \\
\hline 9 & 8 & 32 & 5 & 0.0205 & 0.55 & 0.77 & 50 & 6 & 24 & 7 & 0.0290 & 0.84 & 0.92 \\
\hline 10 & 7 & 14 & 5 & 0.0205 & 0.62 & 1.00 & 51 & 6 & 18 & 7 & 0.0290 & 0.85 & 0.94 \\
\hline 11 & 6 & 12 & 5 & 0.0206 & 0.61 & 1.00 & 52 & 6 & 18 & 7 & 0.0290 & 0.86 & 0.94 \\
\hline 12 & 7 & 14 & 5 & 0.0206 & 0.64 & 1.00 & 53 & 6 & 24 & 7 & 0.0290 & 0.85 & 0.92 \\
\hline 13 & 8 & 24 & 5 & 0.0206 & 0.56 & 0.76 & 54 & 6 & 24 & 7 & 0.0290 & 0.86 & 0.93 \\
\hline 14 & 6 & 12 & 5 & 0.0206 & 0.64 & 1.00 & 55 & 8 & 16 & 9 & 0.0362 & 0.66 & 0.90 \\
\hline 15 & 7 & 21 & 5 & 0.0207 & 0.64 & 0.84 & 56 & 8 & 16 & 9 & 0.0364 & 0.67 & 0.89 \\
\hline 16 & 6 & 12 & 5 & 0.0207 & 0.66 & 1.00 & 57 & 7 & 14 & 9 & 0.0365 & 0.76 & 1.00 \\
\hline 17 & 8 & 32 & 5 & 0.0207 & 0.56 & 0.77 & 58 & 8 & 24 & 9 & .0365 & 0.66 & 0.80 \\
\hline 18 & 7 & 28 & 5 & 0.0207 & 0.65 & 0.81 & 59 & 8 & 32 & 9 & 0.0366 & 0.66 & 0.82 \\
\hline 19 & 7 & 28 & 5 & 0.0207 & 0.65 & 0.81 & 60 & 8 & 16 & 9 & 0.0366 & 0.69 & 0.86 \\
\hline 20 & 7 & 28 & 5 & 0.0207 & 0.65 & 0.81 & 61 & 7 & 21 & 9 & 0.0367 & 0.77 & 0.88 \\
\hline 21 & 7 & 21 & 5 & 0.0208 & 0.65 & 0.83 & 62 & 8 & 24 & 9 & 0.0367 & 0.67 & 0.81 \\
\hline 22 & 6 & 18 & 5 & 0.0208 & 0.75 & 0.93 & 63 & 8 & 32 & 9 & 0.0368 & 0.67 & 0.83 \\
\hline 23 & 6 & 24 & 5 & 0.0208 & 0.75 & 0.88 & 64 & 7 & 14 & 9 & 0.0368 & 0.78 & 0.98 \\
\hline 24 & 6 & 18 & 5 & 0.0208 & 0.77 & 0.93 & 65 & 7 & 28 & 9 & 0.0368 & 0.77 & 0.88 \\
\hline 25 & 6 & 24 & 5 & 0.0208 & 0.77 & 0.89 & 66 & 7 & 14 & 9 & 0.0368 & 0.79 & 0.96 \\
\hline 26 & 6 & 18 & 5 & 0.0209 & 0.78 & 0.92 & 67 & 6 & 12 & 9 & 0.0368 & 0.80 & 1.00 \\
\hline 27 & 6 & 24 & 5 & 0.0209 & 0.78 & 0.89 & 68 & 8 & 24 & 9 & 0.0369 & 0.69 & 0.81 \\
\hline 28 & 8 & 16 & 7 & 0.0282 & 0.59 & 0.93 & 69 & 6 & 12 & 9 & 0.0369 & 0.82 & 1.00 \\
\hline 29 & 8 & 16 & 7 & 0.0284 & 0.61 & 0.90 & 70 & 8 & 32 & 9 & 0.0369 & 0.68 & 0.84 \\
\hline 30 & 7 & 14 & 7 & 0.0284 & 0.67 & 1.00 & 71 & 7 & 21 & 9 & 0.0370 & 0.78 & 0.88 \\
\hline 31 & 8 & 24 & 7 & 0.0284 & 0.59 & 0.79 & 72 & 6 & 12 & 9 & 0.0370 & 0.83 & 1.00 \\
\hline 32 & 8 & 32 & 7 & 0.0285 & 0.59 & 0.79 & 73 & 7 & 28 & 9 & 0.0370 & 0.78 & 0.89 \\
\hline 33 & 8 & 16 & 7 & 0.0286 & 0.62 & 0.86 & 74 & 6 & 24 & 9 & 0.0370 & 0.92 & 0.96 \\
\hline 34 & 8 & 24 & 7 & 0.0286 & 0.61 & 0.78 & 75 & 6 & 18 & 9 & 0.0370 & 0.92 & 0.97 \\
\hline 35 & 7 & 21 & 7 & 0.0286 & 0.70 & 0.86 & 76 & 7 & 21 & 9 & 0.0370 & 0.79 & 0.91 \\
\hline 36 & 8 & 32 & 7 & 0.0286 & 0.61 & 0.80 & 77 & 7 & 28 & 9 & 0.0371 & 0.79 & 0.89 \\
\hline 37 & 7 & 14 & 7 & 0.0286 & 0.72 & 0.99 & 78 & 6 & 18 & 9 & 0.0371 & 0.93 & 0.97 \\
\hline 38 & 7 & 28 & 7 & 0.0287 & 0.70 & 0.84 & 79 & 6 & 18 & 9 & 0.0371 & 0.94 & 0.97 \\
\hline 39 & 7 & 14 & 7 & 0.0287 & 0.72 & 0.96 & 80 & 6 & 24 & 9 & 0.0371 & 0.93 & 0.97 \\
\hline 40 & 6 & 12 & 7 & 0.0287 & 0.73 & 1.00 & 81 & 6 & 24 & 9 & 0.0371 & 0.94 & 0.97 \\
\hline 41 & 8 & 24 & 7 & 0.0287 & 0.62 & 0.78 & & & & & & & \\
\hline
\end{tabular}

